\title{
CONTROL AND ENERGY SAVINGS OF THE PETLYUK DISTILLATION SYSTEM
}

\author{
Juan Pablo Rodríguez ${ }^{1}$, Ernestina Moreno ${ }^{2}$, Juan Gabriel Segovia - Hernández ${ }^{1}$, \\ Arturo Jiménez ${ }^{2}$, Rafael Maya - Yescas ${ }^{3}$ \\ ${ }^{1}$ Universidad de Guanajuato, Facultad de Ciencias Químicas, Guanajuato, Gto.México \\ ${ }^{2}$ Instituto Tecnológico de Celaya, Departamento de Ingeniería Química, Celaya, Gto. México \\ ${ }^{3}$ Universidad Michoacana (UMSNH), Facultad de Ingeniería Química, Morelia, Mich. México
}

\begin{abstract}
The Petyuk distillation system has gained considerable attention because of the energy savings it can provide with respect to the conventional distillation sequences. Since the structure of the Petlyuk system is more complex, its controllability properties may be adverse with respect to the conventional systems. In this work a closed-loop analysis of the Petlyuk distillation system is presented. Special attention is given to show how the control properties change when different operating conditions are used. The results show that the control properties of the Petlyuk column can improve if some degradation in the energy consumption level is allowed. Copyright $\odot 2007$ IFAC
\end{abstract}

Keywords: Closed-loop control, controllability, distillation, Petlyuk column, energy savings.

\section{INTRODUCTION}

The yearly cost of many chemical processes is noticeably affected by the energy consumption of their distillation processes. This fact has promoted the search for separation alternatives that provide better energy efficiencies than the conventional distillation sequences. One such option is the use of thermally coupled distillation sequences. Through the use of liquid-vapor interconnecting streams between two columns, two major effects can be obtained; one, the elimination of one heat transfer equipment from the distillation system, and two, a reduction in the energy consumption of the distillation process. For the separation of ternary mixtures, three schemes have received particular attention, the system with a side recitifier, the system with a side stripper, and the fully thermally coupled system, or Petlyuk column. Such systems have been shown to provide significant energy savings with respect to the conventional direct and indirect distillation sequences. The Petlyuk column (Petlyuk et al., 1965) consists of a prefractionator followed by a main column from which three product streams are obtained (see Figure 1), and this arrangement has been shown to provide higher energy savings than the systems with side columns, with savings of up to $30 \%$ when compared to conventional schemes (Glinos and Malone, 1988; Fidkowski and Krolikowski, 1990). Such results have promoted the development of more formal design methods, such as those reported by Triantafyllou and Smith (1992), Hernández and Jiménez (1999a), Amminudin et al. (2001), and Muralikrishna et al. (2002).

To promote a stronger potential for its industrial implementation, a proper understanding of the operation and control properties of the Petlyuk system are also needed. With two recycle streams and a main column from which three product streams are obtained, the Petlyuk column exhibits a more complex structure than the conventional direct and indirect sequences, which has influenced the expectation that its control properties might be rather difficult. Some research efforts have been conducted to provide some understanding of the dynamic properties of the Petlyuk column (Wolff and Skogestad, 1995; Abdul-Mutalib and Smith, 1998; Hernández and Jiménez, 1999b; Jiménez et al, 2001; 


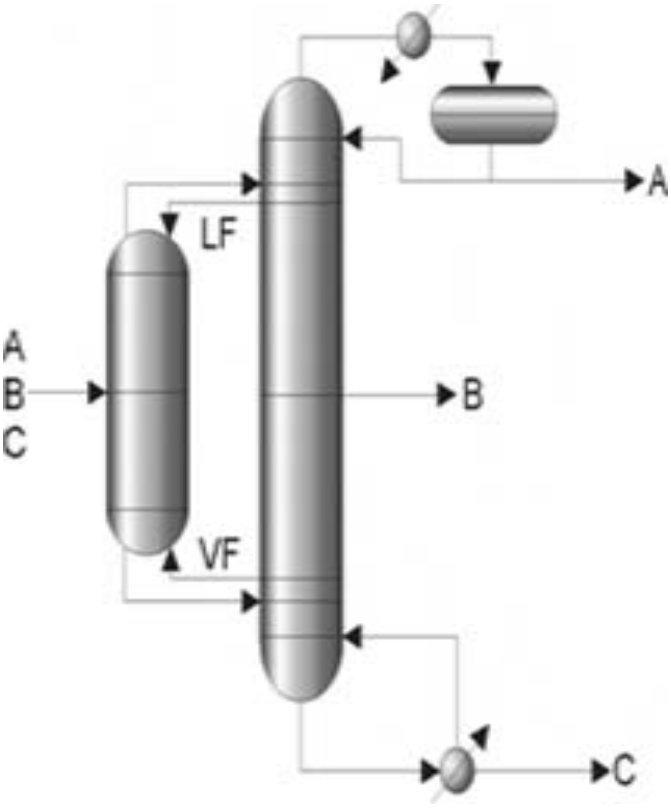

Fig. 1. Structure of the Petlyuk column.

Serra et al, 2003). In general, the results from these works seem to indicate that the control properties of the Petlyuk system are not as troublesome as originally expected. Its implementation in the form of a divided wall column has gained considerable attention from the process industries in recent times (Schultz et al., 2006).

In this work, a feedback control analysis for the Petlyuk column under different operating conditions is reported. Those results are integrated with the energy savings achieved to provide a set of potential operating points from which one can detect a proper compromise between the energy efficiency of the distillation process and its controllability properties.

\section{CONTROL OF THE PETLYUK COLUMN}

Clearly, the operating point under which the Petlyuk column shows minimum energy consumption is of primary importance. However, one may analyze alternative operating points to see how the control properties of the system change and take advantage of any potential improvement in the operability of the process. The basic idea is that if one deviates from the optimal point for energy consumption, the control properties of the Petlyuk system may improve. The work by Serra et al. (2003) showed some preliminary results on this idea; moving away from the operating point with minimum energy consumption, they showed that the theoretical controllability properties of the system, measured through the application of the singular value decomposition technique, can be improved at the expense of lower efficiencies in energy consumption. In this work, we carry out an analysis on the control performance of the Petlyuk system at different operating points, including the one with minimum energy consumption. The control properties are analyzed through closed-loop dynamic responses.
A base design for the Petlyuk column must first be obtained. The design method reported by Hernández and Jiménez (1999a) was used for that purpose. A sequence of three conventional columns (a prefractionator followed by two binary separation columns) is designed, and through a procedure of sections analogy the basic structure of the Petlyuk system is obtained. After a validation process with some commercial software, the design is optimized for energy consumption through a search procedure on the two interconnecting streams, LF and VF (see Figure 1), or on any other two design variables that consume the two degrees of freedom for the system. Figure 2 shows a typical search procedure to detect the conditions under which the point of minimum energy consumption is obtained. The design and the operating conditions for minimum energy consumption constitute the basic information for the dynamics and control analysis. Some changes in the operating conditions are then implemented to see how they affect the energy consumption of the process and its closed-loop responses under feedback control.

\section{CASE OF STUDY}

A ternary mixture of n-pentane (A), n-hexane (B) and n-heptane (C) was chosen as case study. A feed with low content of the intermediate component (mole fraction for $\mathrm{A}, \mathrm{B}$, and $\mathrm{C}$ equal to $0.4,0.2$, and 0.4 , respectively) was assumed; this type of feed composition has been shown to provide the most significant energy savings for thermally coupled distillation sequences. The feed flowrate was assumed as $100 \mathrm{lbmoles} / \mathrm{h}$. The design pressure was chosen so that cooling water could be used in the condenser of the Petlyuk system. Thermodynamic properties were calculated using the Chao-Seader correlations. The molar percent of the main components in each product streams were 98.7, 98.0 and 98.6 for A, B and C, respectively.

\section{RESULTS AND DISCUSSION}

The first step was to obtain the design structure of the Peltyuk sequence and detect the base operating conditions for the best energy efficiency of the system. Table 1 shows the tray structure and other details of the design of the Petlyuk column with minimum energy consumption, which amounts to 1.606 MBTU/h The control analysis was conveyed taking the optimal values for the interconnecting streams and then assuming operating points above and below those values.

The control loops were chosen such that the product streams $\mathrm{A}, \mathrm{B}$, and $\mathrm{C}$ were regulated with the reflux flowrate, the intermediate product flowrate, and the reboiler heat duty, respectively. For the closed-loop control studies, PI controllers were considered, and their parameters were tuned from the minimization of the integral of the absolute error (IAE) criterion. This control strategy has been used in earlier works with 


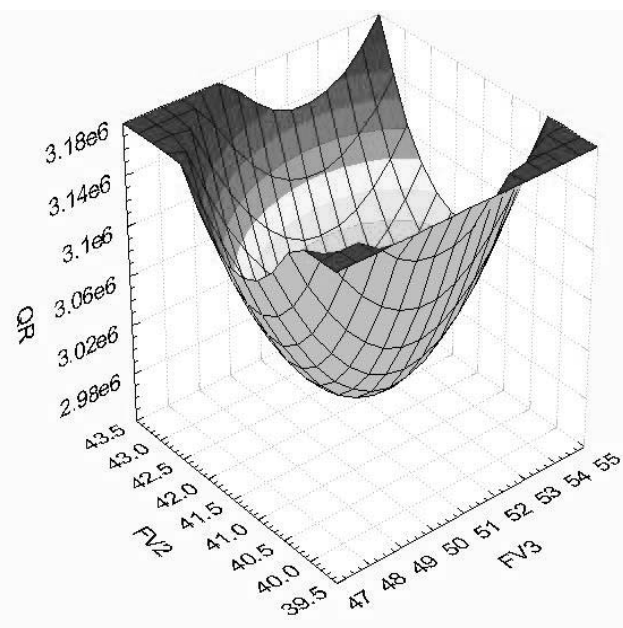

Fig. 2. Optimization of the Petlyuk system.

Table 1. Design obtained for the Petlyuk column

\begin{tabular}{|c|c|}
\hline \multicolumn{2}{|c|}{ Prefractionator } \\
\hline Stages & 17 \\
\hline Feed stage & 9 \\
\hline Pressure (Top, psi) & 21.075 \\
\hline Pressure (Bottom, psi) & 26.075 \\
\hline \multicolumn{2}{|c|}{ Main Column } \\
\hline Stages & 36 \\
\hline Vapor feed stage & 10 \\
\hline Liquid feed stage & 27 \\
\hline Liquid sidestream stage & 17 \\
\hline Condenser duty (MBTU/h) & 1.657 \\
\hline Reflux ratio & 2.78 \\
\hline Reboiler duty (MBTU/h) & 1.606 \\
\hline Pressure (Top, psi) & 21.075 \\
\hline Pressure (Bottom, psi) & 26.075 \\
\hline Temperature (Top, $\left.{ }^{\circ} \mathrm{F}\right)$ & 119.72 \\
\hline Temperature (Bottom, ${ }^{\circ} \mathrm{F}$ ) & 241.48 \\
\hline
\end{tabular}

fairly good results. The details of the control structure and the tuning method for the parameters of the controllers can be found in Segovia-Hernández et al., (2002). Aspen Dynamics 11.1 was used as the software tool for the results here presented.

The approach to analyze the system was as follows. The column was first assumed to operate at the conditions of minimum energy consumption, and a set point change in the composition of each product stream was implemented. From the closed-loop dynamic response, the integral of the absolute error was calculated. Then, several changes in the operating points were implemented, leading each of them to a less energy-efficient operation of the system. These conditions were imposed by changing the value of the interconnecting streams (which changes the operating reflux ratio and other operating conditions); similar set point changes as those assumed for the point with minimum energy consumption were then implemented. New values of the IAE were obtained, which together with the energy consumption levels provide the basis for the assessment of the different operating conditions as far as their compromise between controllability and energy efficiency of the Petlyuk column.

Table 2 shows the results obtained. The minimum energy consumption of $1.606 \mathrm{MBTU} / \mathrm{h}$ for the system implies that the values of the flowrates for the interconnecting streams are 36,000 $\mathrm{lbmoles} / \mathrm{h}$ for the liquid interconnection, and 83,000 lbmoles/h for the vapor interconnection. The IAE values for the set point changes implemented on each control loop are given in Table 2. Changes in the operating point of the column were then implemented. It was chosen to increase or decrease the values of the flowrates for the interconnecting streams by $5,000 \mathrm{lbmoles} / \mathrm{h}$. Notice that if one changes the value for one of the interconnecting streams, the other one must also be changed by the same amount to preserve the overall mass balance for the system (i.e. to preserve the original outputs and compositions for the design problem). For each of the operating points given in Table 2, the parameters of the PI controllers were tuned to provide a fair comparison of the closed-loop results.

One can observe how the energy consumption of the distillation system increases as the values for the interconnecting streams were raised, but the controllability of the system improved until it reached a point with minimum IAE values. Thus, when the liquid interconnecting stream FL goes from the optimum value of $36,000 \mathrm{lbmoles} / \mathrm{h}$ to 51,000 lbmoles/h (an increase of $41.7 \%$ ), the IAE values for the control loops decrease in $29 \%$ for product A, $9.6 \%$ for product $\mathrm{B}$, and $13.8 \%$ for product $\mathrm{C}$. This improvement in the closed-loop performance of the column is obtained at the expense of a $5 \%$ increase in

Table 2. Energy consumption and IAE results for different operating conditions

\begin{tabular}{|c|c|c|c|c|}
\hline $\begin{array}{c}\mathrm{FL}, 10^{3} \\
(\mathrm{lbmol} / \mathrm{h})\end{array}$ & $\begin{array}{c}\mathrm{FV}, 10^{3} \\
(\mathrm{lbmol} / \mathrm{h})\end{array}$ & $\begin{array}{l}\text { Heat duty } \\
\text { (MBTU/h) }\end{array}$ & Loop & $\begin{array}{l}\text { IAE } \\
\left(10^{-4}\right)\end{array}$ \\
\hline \multirow{3}{*}{21} & \multirow{3}{*}{68} & \multirow{3}{*}{2.705} & $\mathrm{~A}$ & 1.353 \\
\hline & & & B & $* *$ \\
\hline & & & $\mathrm{C}$ & 0.273 \\
\hline \multirow{3}{*}{26} & \multirow{3}{*}{73} & \multirow{3}{*}{1.944} & A & 1.662 \\
\hline & & & B & 12.12 \\
\hline & & & $\mathrm{C}$ & $* *$ \\
\hline \multirow{3}{*}{31} & \multirow{3}{*}{78} & \multirow{3}{*}{1.654} & A & 1.772 \\
\hline & & & B & $* *$ \\
\hline & & & $\mathrm{C}$ & 0.395 \\
\hline \multirow{3}{*}{36} & \multirow{3}{*}{83} & \multirow{3}{*}{1.606} & A & 1.764 \\
\hline & & & B & 1.890 \\
\hline & & & $\mathrm{C}$ & 0.425 \\
\hline \multirow{3}{*}{41} & \multirow{3}{*}{88} & \multirow{3}{*}{1.625} & A & 1.742 \\
\hline & & & B & 1.556 \\
\hline & & & $\mathrm{C}$ & 0.407 \\
\hline \multirow{3}{*}{46} & \multirow{3}{*}{93} & \multirow{3}{*}{1.662} & A & 1.700 \\
\hline & & & B & 1.419 \\
\hline & & & $\mathrm{C}$ & 0.393 \\
\hline \multirow{3}{*}{51} & \multirow{3}{*}{98} & \multirow{3}{*}{1.694} & A & 1.247 \\
\hline & & & B & 1.708 \\
\hline & & & $\mathrm{C}$ & 0.366 \\
\hline
\end{tabular}

** convergence not achieved 
column is obtained at the expense of a $5 \%$ increase in the energy consumption of the distillation process (from 1.606 to $1.694 \mathrm{MBTU} / \mathrm{h}$ ). The overall energy efficiency of the system, however, should be viewed as a combination of the energy requirements at the steady state values and the control properties that are used to adjust the system towards the steady state conditions in the face of disturbances or set point changes. In other words, the energy efficiency deterioration of the system should be lower than the $5 \%$ value that was computed just from the energy consumption required at the steady state conditions, given the improvement that is obtained in the process controllability.

When a decrease in the values of the interconnecting streams was explored, convergence towards the new steady states was not achieved, meaning that the controllability of the system becomes an issue at those alternating conditions.

For this case, therefore, the best strategy would be to operate the system at values of the interconnecting streams higher than those that provide the optimal steady-state condition for minimum energy consumption.

\subsection{Use of other control loops}

The control loops selected for this analysis were based on the extension of practical considerations that have been used for conventional distillation sequences. It is well known that the control performance of a distillation column is affected by the selection of the control configuration (see for instance Hurowitz et al., 2003). To explore this situation further, the relative gain array (RGA) method was applied to the Petlyuk system to see if a new loop-pairing was suggested by such a technique. The transfer function matrix for the Petlyuk column was used to obtain the RGA structure. The resulting RGA matrix suggested pairing the control of the distillate product with the reboiler heat duty and the bottoms product with the reflux flowrate. The control of the composition of the intermediate component remained the same.

Although they do not seem very conventional, the alternative control loops as suggested by the RGA results were used to perform a similar sensitivity analysis on the dynamics of the system under different operating points. Table 3 shows the results obtained for the dynamic responses of the products with the lightest and the heaviest components, for which different control loops were used. It can again be observed how the closed-loop performance improves as the values of the interconnecting flows are gradually increased over the values that provide a minimum energy consumption.

Under this control configuration, an increase in the value of the liquid interconnecting stream FL of $41.7 \%$ (from 36,000 to $51,000 \mathrm{lbmoles} / \mathrm{h}$ ), which provides a $5.5 \%$ increase in energy consumption of the Petlyuk system, yields a noticeable improvement in the dynamic performance of the system, in particular for the control of the lightest component;
Table 3. Energy consumption and IAE values obtained with the use of alternative control loops

\begin{tabular}{|c|c|c|c|c|}
\hline $\begin{array}{c}\mathrm{FL}, 10^{3} \\
(\mathrm{lbmol} / \mathrm{h})\end{array}$ & $\begin{array}{c}\mathrm{FV}, 10^{3} \\
(\mathrm{lbmol} / \mathrm{h})\end{array}$ & $\begin{array}{l}\text { Heat duty } \\
\text { (MBTU/h) }\end{array}$ & Loop & $\begin{array}{l}\text { IAE } \\
\left(10^{-4}\right)\end{array}$ \\
\hline \multirow[t]{2}{*}{21} & \multirow[t]{2}{*}{68} & \multirow[t]{2}{*}{2.705} & A & 3.201 \\
\hline & & & $\mathrm{C}$ & 1.980 \\
\hline \multirow[t]{2}{*}{26} & \multirow[t]{2}{*}{73} & \multirow[t]{2}{*}{1.944} & A & 4.824 \\
\hline & & & $\mathrm{C}$ & 2.224 \\
\hline \multirow[t]{2}{*}{31} & \multirow[t]{2}{*}{78} & \multirow[t]{2}{*}{1.654} & A & 6.436 \\
\hline & & & $\mathrm{C}$ & 2.330 \\
\hline \multirow[t]{2}{*}{36} & \multirow[t]{2}{*}{83} & \multirow[t]{2}{*}{1.606} & A & 6.872 \\
\hline & & & $\mathrm{C}$ & 2.521 \\
\hline \multirow[t]{2}{*}{41} & \multirow[t]{2}{*}{88} & \multirow[t]{2}{*}{1.625} & A & 6.724 \\
\hline & & & $\mathrm{C}$ & 2.601 \\
\hline \multirow[t]{2}{*}{46} & \multirow[t]{2}{*}{93} & \multirow[t]{2}{*}{1.662} & A & 6.460 \\
\hline & & & $\mathrm{C}$ & 2.611 \\
\hline \multirow[t]{2}{*}{51} & \multirow[t]{2}{*}{98} & \multirow[t]{2}{*}{1.694} & A & 2.276 \\
\hline & & & $\mathrm{C}$ & 2.593 \\
\hline
\end{tabular}

a $67 \%$ improvement in the IAE value for the control of the top product stream of the column is observed. This means that the column will operate out of specifications for a shorter amount of time with respect to the point with minimum energy consumption when closed-loop responses are needed as part of servo or disturbance-rejection situations.

It is interesting to notice that under the operation with these alternative control loops, the feasible operating range of the columns seems to be higher. This observation arises from the results obtained when the values for the interconnecting streams were lowered. In contrast to the performance of the column under the first set of control loops, convergence was obtained in the dynamic simulations towards the new steady state, along with an improvement in the IAE values with respect to the operating point with minimum energy consumption under these control loops; the heat load required for the separation, however, increases more rapidly than moving the operating point in the other direction. Also, another relevant observation has to do with the IAE values obtained under the operation of each set of control loops. The base performance of the column at the point with minimum energy consumption was better with the more conventional control loops assumed in the first set of runs (Table 1 ), and so were the other dynamic responses, including the one at the operating point with a $5.5 \%$ increase in energy consumption. Therefore, the first set of control loops would be recommended over the one suggested by the RGA technique. In general, the results for the case study have shown that operating the Petlyuk system at values of the interconnecting streams higher than those for the optimal point for energy consumption provides a better design policy if operability aspects are taken into account.

\section{CONCLUSIONS}

The Petlyuk distillation provides significant energy savings with respect to the conventional direct and 
indirect distillation sequences for the separation of ternary mixtures. Its more complex structure requires a special analysis to ensure its operability and controllability properties for a more established industrial implementation. In this work, an analysis of the performance of the Petlyuk system under different operating conditions has been presented. The effect of such conditions on both energy requirements and closed-loop performance was analyzed. It was found that operating the column at conditions different from the point with minimum energy consumption can lead to designs with better feedback control performance. Although the energy efficiency of the system is deteriorated, it can still be preserved at a fairly high level since the improvement in dynamic performance would require a degradation in the energy consumption between 1 and $5 \%$. Following the type of approach here presented for thermally coupled distillation systems, one can arrive at energy-efficient designs that do not necessarily conflict with their operating capabilities.

\section{ACKNOWLEDGEMENTS}

Financial support from Conacyt, México, for the development of this project is gratefully acknowledged.

\section{REFERENCES}

Abdul-Mutalib, M. I. and R. Smith (1998). Operation and Control of Dividing Wall Distillation Columns. Part I: Degrees of Freedom and Dynamic Simulation, Trans Inst. Chem. Eng., 76, 308-318.

Amminudin, K. A., R. Smith, D.Y.-C. Thong and G.P. Towler (2001). Design and Optimization of Fully Thermally Coupled Distillation Columns. Part I: Preliminary Design and Optimization Methodology, Trans Inst. Chem. Eng., 79, 701-715.

Fidkowski, Z. and L. Krolikowski (1990). Energy Requirements of Nonconventional Distillation Systems, AIChE J., 36, 1275-1278.

Glinos, K. and M.F. Malone (1988). Optimality Regions for Complex Column Alternatives in Distillation Systems, Chem. Eng. Res. Des., 66, 229-240.

Hernández, S. and A. Jiménez (1999a). Design of Energy Efficient Petlyuk Systems, Comput. Chem. Eng., 23, 1005-1010.

Hernández, S. and A. Jiménez (1999b). Controllability Analysis of Thermally Coupled Distillation Systems, Ind. Eng. Chem. Res., 38, 3957-3963.

Hurowitz, S.E., J. Anderson, M. Duval and J.B. Riggs (2003). Distillation control configuration selection, Journal of Process Control, 13, 357362.

Jiménez, A., S. Hernández, F.A. Montoy and M. Zavala-García (2001). Analysis of Control Properties of Conventional and Nonconventional Distillation Sequences, Ind. Eng. Chem. Res., 40, 3757-3761.
Muralikrishna, K., K.P. Madhavan and S.S. Shah (2002). Development of Dividing Wall Distillation Column Design Space for a Specified Separation, Trans Inst. Chem. Eng., 80, 155-166.

Petlyuk, F. B., V.M. Platonov and D.M. Slavinskii (1965). Thermodinamically Optimal Method for Separating Multicomponent Mixtures, Inter. Chem. Eng., 5, 555-561.

Triantafyllou, C. and R. Smith (1992). The Design and Optimization of Fully Thermally Coupled Distillation Columns, Trans Inst. Chem. Eng., 70, 118-132.

Schultz, M A., D.E. O'Brien, R.K. Hoehn, C.P. Luebke and D.G. Stewart (2006). Innovative flowschemes using dividing wall columns, In Proceedings of European Symposium on Computer Aided Process Engineering - 16 (ESCAPE), (Wolfgang Marquardt and Costas Pantelides. (Ed)), 1353-1358. Elsevier, Germany.

Segovia-Hernández, J.G., S. Hernández and A. Jiménez (2002). Control behaviour of thermally coupled distillation sequences, Trans Inst. Chem. Eng., 80, 783-789.

Serra, M., A. Espuña and L. Puigjaner (2003). Controlability of Different Multicomponent Distillation Arrangements. Ind. Eng. Chem. Res., 42, 1773-1782.

Wolff, E. A. and S. Skogestad (1995). Operation of Integrated Three - Product (Petlyuk) Distillation Columns, Ind. Eng. Chem. Res., 34, 2094-2103. 
